\title{
Fixation of osteochondral fragments in the human knee using Meniscus Arrows
}

\author{
Diederick B. Wouters · Johannes G. M. Burgerhof • \\ Jeff. T. M. de Hosson • Rudolf R. M. Bos
}

Received: 27 December 2009/ Accepted: 19 April 2010/Published online: 13 May 2010

(C) The Author(s) 2010. This article is published with open access at Springerlink.com

\begin{abstract}
The aim of this study is to compare the hold in bone of Meniscus Arrows ${ }^{\circledR}$ and Smart Nails ${ }^{\circledR}$, followed by the report of the results of the clinical application of Meniscus Arrows ${ }^{\circledR}$ as fixation devices. First, pull-out tests were performed to analyse the holdfast of both nails in bone. Statistical analysis showed no significant difference; therefore, the thinner Meniscus Arrow ${ }^{\circledR}$ was chosen as fixation device in the patient series of two patients with a symptomatic Osteochondritis dissecans fragment and three patients with an osteochondral fracture of a femur condyle. The cartilage margins were glued with Tissuecoll ${ }^{\circledR}$. All fragments consolidated. Second look arthroscopy in three patients showed fixed fragments with stable, congruent cartilage edges. At an average follow-up period of 5 years no pain, effusion, locking, restricted range of motion or signs of osteoarthritis were reported. Based on the results of the pull-out tests and available clinical studies, Meniscus
\end{abstract}

\footnotetext{
D. B. Wouters $(\bowtie)$

Department of General, Arthroscopic Surgery

and Traumatology, TweeSteden Hospital, Dr. Deelenlaan 5, 5042 AD Tilburg, The Netherlands

e-mail:dwouters@tsz.nl

D. B. Wouters · R. R. M. Bos

Department of Oral and Maxillofacial Surgery,

University Medical Centre Groningen, Hanzeplein 1,

9713 GZ Groningen, The Netherlands

J. G. M. Burgerhof

Department of Epidemiology, University Medical

Centre Groningen, Hanzeplein 1, 9713 GZ Groningen,

The Netherlands

Jeff. T. M. de Hosson

Department of Applied Physics, University of Groningen,

Nijenborgh 4, 9747 AG Groningen, The Netherlands
}

Arrows ${ }^{\circledR}$ and Smart Nails ${ }^{\circledR}$ are both likely to perform adequately as fixation devices in the treatment of Osteochondritis dissecans and osteochondral fractures in the knee. They both provide the advantage of one stage surgery. However, based on their smaller diameter, the Meniscus Arrows ${ }^{\circledR}$ should be preferred for this indication.

Keywords Osteochondritis dissecans .

Osteochondral fragments - Biodegradable .

Fixation devices · Meniscus Arrows ${ }^{\circledR}$

\section{Introduction}

Most of the compressive metallic fixation devices such as screws [5, 16], or staples [11] and non-compressive pins or Kirschner wires [1, 10, 24], used to fix the fragments in the treatment of Osteochondritis dissecans (OCD), have to be removed during a second procedure to prevent damage to the opposite cartilage.

Even devices, embedded under the cartilage surface to prevent cartilage damage, can protrude after all. Another disadvantage of permanent implantation of metallic devices is scattering during CT or MRI scanning, interference with radiation therapy, evocation of local allergic reactions like eczema and their potential carcinogenicity [2, 3, 20].

Autologeous cartilage bone plugs are used as fixation devices as well. However, donor site morbidity, the absence of producing substantial compression and failure of the re-integration process at the interface of donor and recipient cartilage make this procedure less than optimal $[12,17]$.

The use of biodegradable fixation devices would avoid these previously mentioned disadvantages and makes a removal operation unnecessary. 
Biodegradable pins, nails and screws of polydioxanon, polyglycolic acid and polylactic acid, their co-polymers, combinations or blends are now in use for small fragment fixation in fracture or OCD treatment. Each of these materials and devices has shortcomings. Biodegradable barbed nails such as Smart Nails ${ }^{\circledR}$ (ConMed Linvatec Ltd., Tampere, Finland), $1.5 \mathrm{~mm}$ in diameter, have currently been used for fragment fixation in patients with OCD fragments and, according to these papers, perform better than pins $[7,25]$.

Meniscus Arrows ${ }^{\circledR}$ (ConMed Linvatec Ltd Tampere, Finland) and Smart Nails ${ }^{\circledR}$ are both manufactured from the same self-reinforced poly-L-DL (80-20) lactide copolymer.

The smaller Meniscus Arrows ${ }^{\circledR}$ could potentially act as small fragment fixation devices as well. The hold in bone was evaluated during in vitro research, showing a considerable pull-out force, more than 60 Newton $(\mathrm{N})$, out of a human femoral condyle [29].

The purpose of this study was to perform in vitro pull out tests comparing the hold in bone of single Meniscus Arrows ${ }^{\circledR}$ and Smart Nails ${ }^{\circledR}$ and of bone blocks, fixed with three devices of each kind and second, to evaluate the application of Meniscus Arrows ${ }^{\circledR}$ as fixation devices in a clinical study with patients with intact Osteochondritis dissecans fragments and osteochondral fractures of the femoral condyles.

\section{Materials and methods}

The experiment was divided in two parts. First, three single Meniscus Arrows ${ }^{\circledR}$ with a length of $16 \mathrm{~mm}$ and three Smart Nails ${ }^{\circledR}$ with a length of $20 \mathrm{~mm}$ were successively pulled out of a thawed, fresh-frozen human condyle, clamped in an Instron 1195 draw bench (Fig. 1a). The scale was set at
0-200 N, the time $0-300 \mathrm{~s}$. The extraction speed was $5 \mathrm{~mm} / \mathrm{min}$. The standard hand instruments were used to create the holes and to insert the devices.

Second, three bone blocks, each with three Meniscus Arrows ${ }^{\circledR}$ or Smart Nails ${ }^{\circledR}$, were fixed at the condyle and were pulled off in axial direction, as well as in tangential direction (Fig. 1b), mimicking shear forces.

\section{Clinical series}

Two women, respectively 20 years (patient \#1, right knee) and 38 years old (patient \#2, left knee), with a symptomatic and intact OCD fragment of the medial condyle, sized $20 \times 25 \mathrm{~mm}$ in diameter in patient $\# 1$ and $30 \times 30 \mathrm{~mm}$ in patient \#2 were operated between 1999 and 2001, with a follow-up period of 9 and 7 years. Surgery was initiated arthroscopically in both cases, in patient \#1 arthroscopically continued as well. Compressive fixation with three Meniscus Arrows ${ }^{\circledR}, 16 \mathrm{~mm}$ in length, was performed and three additional drill holes were made to give entrance to the bone marrow to promote healing (Fig. 2a). After releasing the tourniquet, bleeding was observed from the drill holes (Fig. 2b).

In patient \# 2, the arthroscopy was converted into a small arthrotomy, due to fragment size, the presence of infra-fragmental necrosis, the necessity for spongeous bone transplantation, proper reduction and required orientation to insert the devices perpendicular to the cartilage surface (Fig. 2c). The fragment was reduced after removal of the interjacent necrosis and spongeous bone placement and was temporarily fixed with $\mathrm{K}$-wires, $1 \mathrm{~mm}$ in diameter. These were subsequently exchanged by five Meniscus Arrows ${ }^{\circledR}$ with a length of $16 \mathrm{~mm}$ (Fig. 2d).
Fig. 1 a The bone block with 3 MA's fixed before being pulled off in axial direction. $\mathbf{b}$ the bone block with 3 MA's fixed before being pulled off, mimicking shear forces
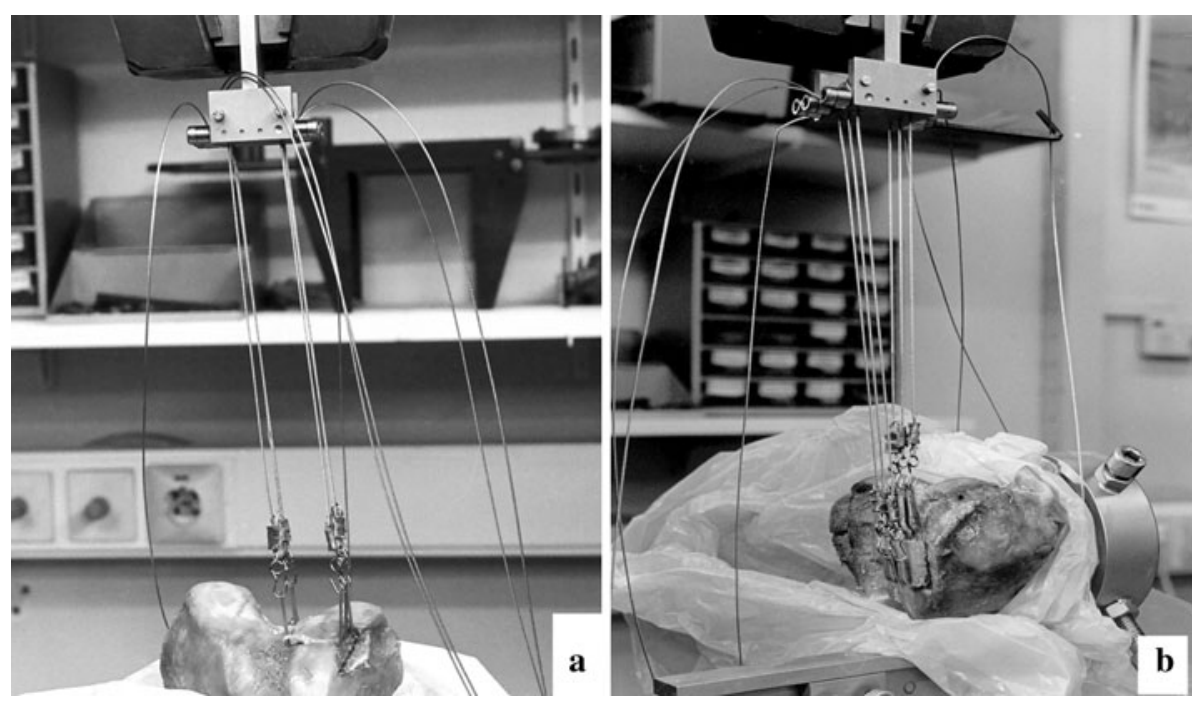
Fig. 2 Patient \#1 a central drilling; b after fixation with 3 Meniscus Arrows ${ }^{\circledR}$ and release of the tourniquet, note the bleeding from a drill hole; patient \#2. c insertion of a Meniscus Arrow ${ }^{\circledR}$ from the lateral portal in the fragment after debridement and a spongeous bone transplantation; d the final situation
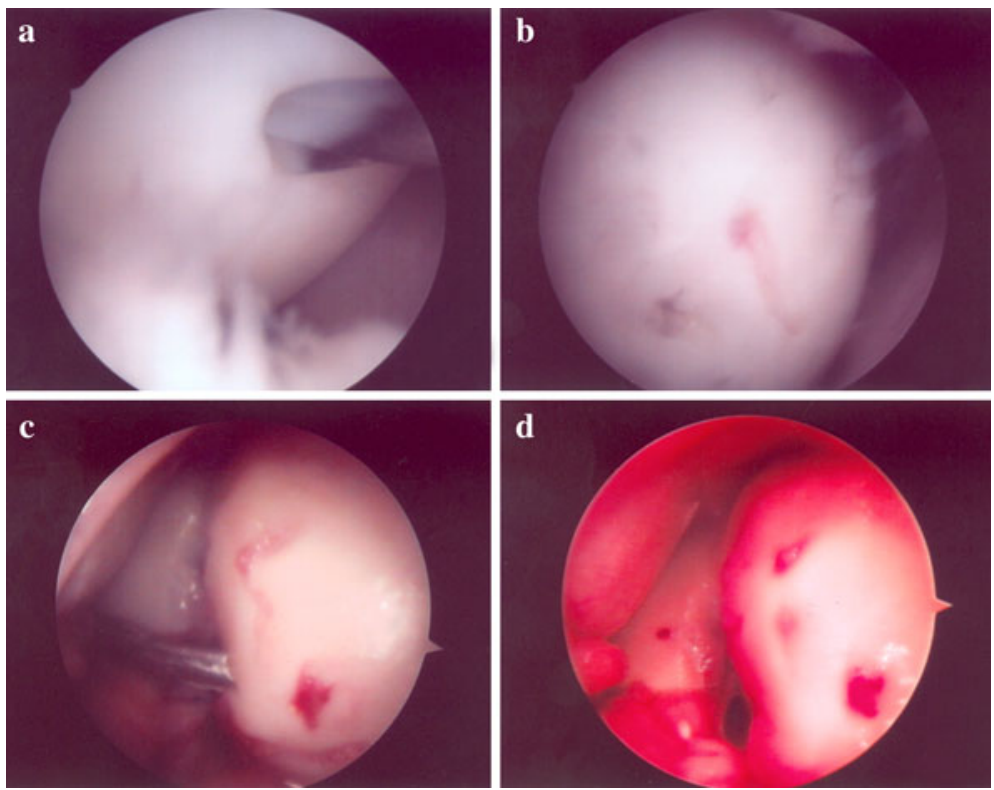
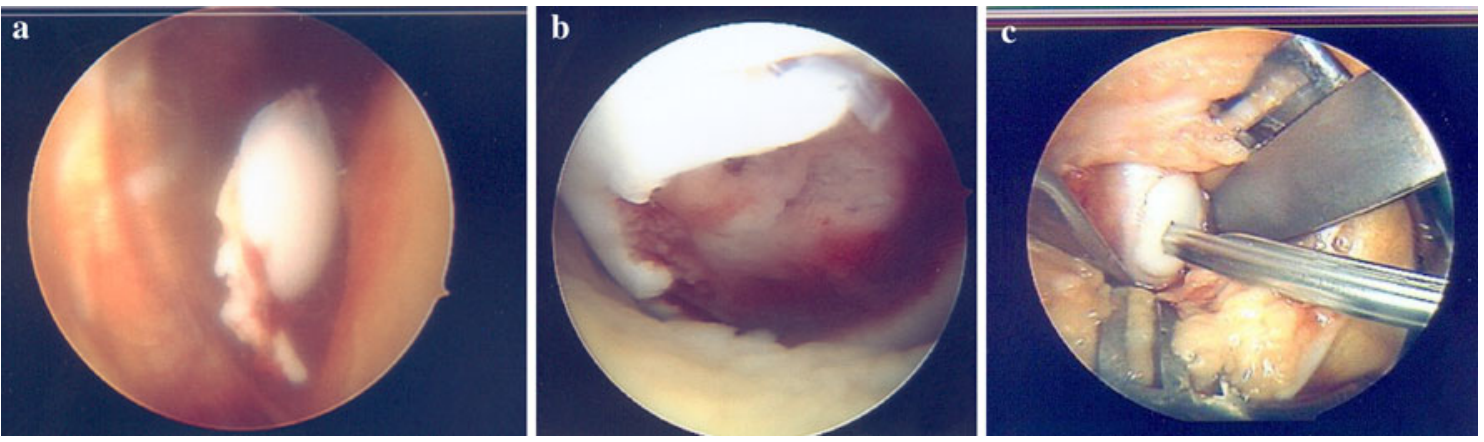

Fig. 3 Patient \# 3: a arthroscopical view of the fragment, b aspect of the defect in the lateral femur condyle, $\mathbf{c}$ fixation with the first Meniscus Arrow ${ }^{\circledR}$

The other patients $(\# 3,4,5)$ were two children of 11 and 15 years old and one adult of 20 years old with a traumatic osteochondral fracture, one time sized $20 \times 30 \mathrm{~mm}$ and twice $25 \mathrm{~mm} \times 30 \mathrm{~mm}$ in diameter. The operation was performed within 2 weeks after the trauma. Tissuecoll ${ }^{\circledR}$ (Baxter-Immuno, Vienna, Austria) was applied on the cartilage borders. The bony fixation was performed using two Meniscus Arrows ${ }^{\circledR}$ (Fig. 3 a-c) in patients \# 3 and \# 4 and five Meniscus Arrows ${ }^{\circledR}$ to obtain sufficient stability and equally distributed compression in patient \# 5 (Fig. 4a-c). Both the arthrotomy and the arthroscopy portals were closed in layers in all patients with Vicryl Rapide ${ }^{\circledR}$ (Johnson \& Johnson, Warsaw, USA).

Postoperatively, a plaster splint was applied for 2 weeks, followed by a hinged brace for 4 weeks. A second look arthroscopy was carried out in the three patients with
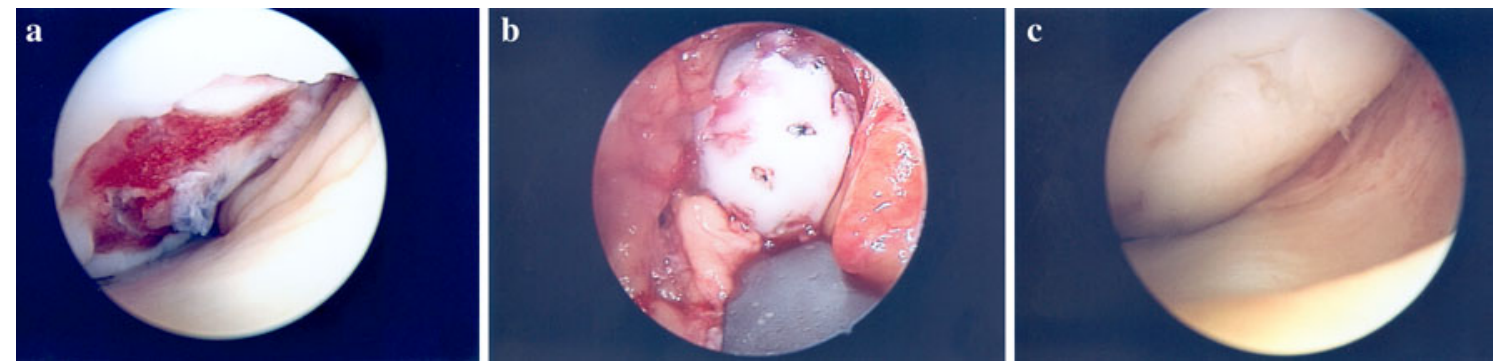

Fig. 4 Patient \#5: a the defect. b fixation with Tissuecoll ${ }^{\circledR}$ and five Meniscus Arrows ${ }^{\circledR}$, $\mathbf{c}$ the result 6 weeks postoperative 
the osteochondral fractures 6 weeks postoperatively before loading the leg, with the consent of the parents, to be sure that the fragment was stable enough to be loaded.

Gradual progressive weight bearing was allowed in the next 4 weeks.

\section{Statistical analysis}

The Student $T$-test and the Mann-Whitney test were used for the single Meniscus Arrows ${ }^{\circledR}$ and Smart Nails ${ }^{\circledR}$. For both groups, the ANOVA two-way tests after the logarithmic transformation and the Levene test of equality of error variances were applied.

Based on the outcome of these tests, we selected the smaller Meniscus Arrows ${ }^{\circledR}$ for the clinical study.

\section{Results}

No effusions, locking, or pain occurred in the two OCD patients during a follow-up period of 7 and 9 years, respectively. The patients did not experience restrictions in daily life or sports activities, although they spontaneously avoided high-impact sports as a precaution.

All three osteochondral fractures healed without sequelae as well. Within 3 months, both children returned to their previous activities. The adult patient (\# 5) returned in 6 months. During a second look arthroscopy 6 weeks postoperatively, consolidation of the fragment was found in all cases, with anatomical alignment of the cartilage. In patient \# 3, the heads of the Meniscus Arrows ${ }^{\circledR}$ were visible and came incidentally loose at the junction between the head and the first barb, after some traction was applied with an arthroscopic forceps. The heads were removed from the joint.

In patient \# 4, the heads of the Meniscus Arrows ${ }^{\circledR}$ were still embedded under the cartilage surface and were stable.

No Meniscus Arrow ${ }^{\circledR}$ heads at all were seen in patient \# 5 at arthroscopy (Fig. 4c).

No wear or damage of the cartilage of the opposite tibia plateau of any of these three patients was observed (Figs. 3, 4).

The pull-out tests showed values of the single Meniscus Arrow ${ }^{\circledR}$ varying between 59 Newton $(\mathrm{N})$ and $78 \mathrm{~N}$ with an average of $68 \mathrm{~N}$. The single Smart Nails ${ }^{\circledR}$ required between 53 and $66 \mathrm{~N}$, the average was $61 \mathrm{~N}$ to be pulledout. The required forces in the bone blocks group to distract the blocks with the Meniscus Arrows ${ }^{\circledR}$ from the condyle varied from $108 \mathrm{~N}$ to $148 \mathrm{~N}$ with an average of $122 \mathrm{~N}$, the blocks with Smart Nails ${ }^{\circledR}$ fixation needed $55-115 \mathrm{~N}$, with an average of $88 \mathrm{~N}$.
All information was combined into one statistical analysis. A two-way ANOVA was performed with the type of nail (Meniscus Arrows ${ }^{\circledR}$ vs. Smart Nails ${ }^{\circledR}$ ) and condition (single nail or bone block) as fixed factors. A logarithmic transformation of the required force was used to equalize variances. Levene's test showed no significant difference in the variances of the transformed variable. As expected, the bone blocks, fixed with 3 devices, required significantly more force to be distracted than the single devices $(P=0.007)$, but no significant difference was found between the Meniscus Arrows ${ }^{\circledR}$ and the Smart Nails ${ }^{\circledR}$.

\section{Discussion}

The most important finding of the present study was the successful and uncomplicated healing of the bony parts and cartilage of OCD dissecans and osteochondral fragments in children adult patients.

In the last five decades, reduction of OCD fragments and osteochondral fractures, if remaining intact, followed by rotation stable fixation with compression, has been generally accepted as the optimal treatment $[1,5,7,8,10,11,14$, $16,21,24,25,27-29]$. A spongeous bone transplantation and debridement of the dissecat bed, if necrosis is found, should be considered in case of Osteochondritis dissecans, regarding the development of OCD as a pseudarthrosis $[1,5,7,8,10,11,13,14,16,21,24,25,27-29]$.

Using biodegradable devices provides the possibility to repair these conditions with a single procedure, avoiding the need of a removal operation.

The application of biodegradable screws, however, has potential disadvantages such as damage to the opposite cartilage from exposed screw heads and, if rapidly degrading material is used, sinus formation [8, 13, 14, 21, 27].

Small barbed pins such as Meniscus Arrows ${ }^{\circledR}$ or Smart Nails ${ }^{\circledR}$ perform better than smooth pins to fix the bony part of the fragment without causing sinus formation [7, 25, 29].

In this study, no statistical difference between the required pull out forces of both the single Meniscus Arrows ${ }^{\circledR}$ and Smart Nails ${ }^{\circledR}$ or between the pull-off forces of the bone blocks fixed with three of each type of device was demonstrated. This can be explained by the same size of the barbs of both devices (Fig. 5). Given their equal mechanical behaviour, combined with reduced tissue damage and option for an increased number and arrangement of Meniscus Arrows ${ }^{\circledR}$, permitted by their smaller diameter, resulting in a more equally distributed pressure on the fragment with equivalent or less damage, we choose for the Meniscus Arrows ${ }^{\circledR}$ for clinical application.

Second look arthroscopy was performed in accordance with the parents of the patients in the three cases of 


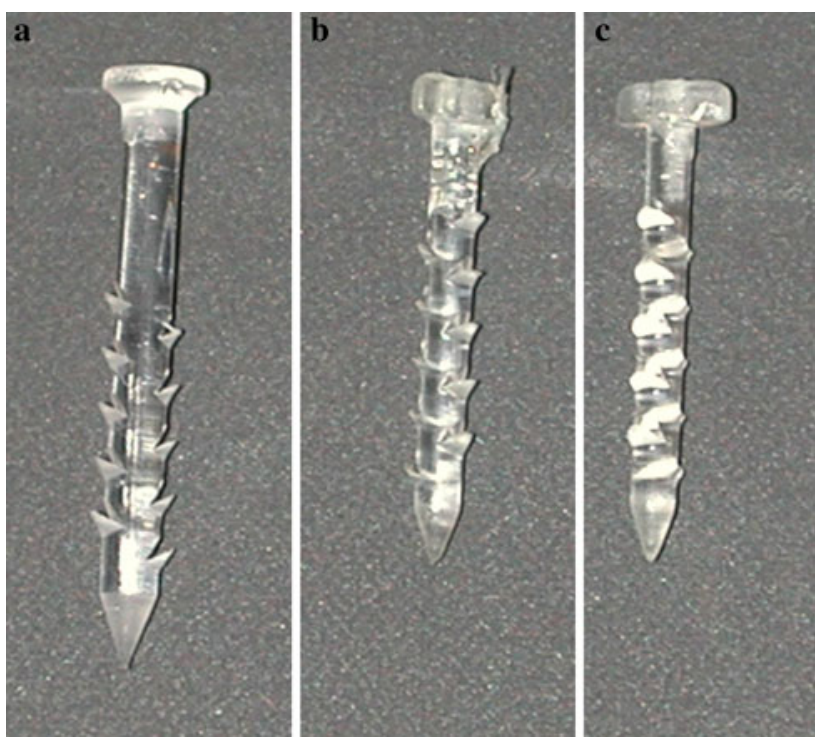

Fig. 5 a A Smart Nail ${ }^{\circledR}$, b, c two Meniscus Arrows ${ }^{\circledR}$, in different directions to show the head and barbs

osteochondral fractures to assess the healing before weight bearing was allowed.

No signs of chondral damage were observed, either at second look arthroscopy or during the follow-up period. This is in accordance with the findings of Weckström et al. [25] and Dines et al. [7]. They did not mention chondral damage in their series with Smart Nails ${ }^{\circledR}$ as fixation devices as well. According to these data and the consistent outcome of the three cases in this study, second look arthroscopy in next cases is not necessary in our opinion with the benefit of the one stage surgery.

In case of intact, bulging cartilage covering the fragment, only compressive fixation and drilling is likely to be sufficient, if no necrosis is emanating from the drill holes, as fond in patient \#1 in our series and in the series, described in the papers of Weckström et al. [25] and Dines et al. [7].

The number of reports of chondral damage while using Meniscus Arrows ${ }^{\circledR}$ in meniscal surgery is a limited number of case reports [19, 22, 23], in contrast with their frequent and worldwide numerous application in orthopaedic procedures $[23,30]$. Similar case reports of chondral damage are also found in relation to other devices, so this phenomenon is not restricted to Meniscus Arrows ${ }^{\circledR}$ alone [4, 9].

The Meniscus Arrow ${ }^{\circledR}$ heads were incidentally removed in patient \# 3 during the second look arthroscopy, while testing their stability with a forceps. In patient \# 4, the heads were stable. In patient \# 5, no heads were found at all. The clinical course, however, was equivalent for all patients, as was with the patients described by Weckström et al. and Dines et al. [7, 25]. At recent arthroscopical treatment of a patella fracture of patient \#4 in the same knee as the osteochondral fracture was fixated 3 years earlier, the Meniscus Arrow ${ }^{\circledR}$ heads were found to be spongy and soft and disintegrating the moment they were touched. This can be the fate of other biodegradable implants in time as well.

The chondral part of the fragment in our three patients with osteochondral fractures was fixed with Tissuecoll ${ }^{\circledR}$, according to recommendations in the literature $[6,18]$ to promote healing. Good and stable congruency was found during control arthroscopy of the cartilage edges.

The OCD disease is a rare condition. Lindèn [15] found an average incidence of one out of 10,000 patients under the age of 50 years in Malmö during a follow-up period of 10 years, with a maximum incidence between the ages of 10 years and 20 years. Widuchowski et al. [26] reported a prevalence of two per cent in a sample of 25,124 arthroscopies. Given the low prevalence of OCD in the population, our series of patients is small, which is a limitation to draw conclusions. However, the undisturbed clinical course in our series using Meniscus Arrows ${ }^{\circledR}$ combined with the results in the clinical series using the even larger Smart Nails ${ }^{\circledR}[7,25]$ supports the application of both types of devices.

The diameter of the Meniscus Arrows ${ }^{\circledR}$ is $26 \%$ smaller, compared to the Smart Nails ${ }^{\circledR}$ (1.1 mm versus $1.5 \mathrm{~mm}$, Fig. 5). The surface of the defect in the fragment for each Meniscus Arrow ${ }^{\circledR}$ is $0.79 \mathrm{~mm}$, compared to $1.77 \mathrm{~mm}$ for each Smart Nail ${ }^{\circledR}$. For three devices, the total damage to the fragment is $2.4 \mathrm{~mm}$ vs. $5.3 \mathrm{~mm}$.

This combined with their excellent hold in bone, at least equal to that of the Smart Nails ${ }^{\circledR}$ as demonstrated during our pull out tests, makes the Meniscus Arrows ${ }^{\circledR}$ arguably the more advantageous device for the fixation of the mostly small OCD fragments and osteochondral fractures.

\section{Conclusion}

Based on the results from in vitro pull-out tests and available clinical studies, Meniscus Arrows ${ }^{\circledR}$ and Smart Nails ${ }^{\circledR}$ are likely to perform adequately in the treatment of both Ostechondritis dissecans disease and osteochondral fractures in the knee. They provide the advantage of onestage surgery. The smaller diameter of the Meniscus Arrows $^{\circledR}$, however, indicates in our opinion that this device should be preferred for this indication. In this study, Meniscus Arrows ${ }^{\circledR}$ allowed undisturbed healing of osteochondral lesions of the knee in five patients without complications.

Acknowledgments We would like to express our gratitude to Mrs. C. M. Houser, MPhil, MD, and Miss P. B. S. Wouters, for their linguistic revision of this manuscript. 
Conflict of interest statement The authors declare that they have no conflict of interest.

Open Access This article is distributed under the terms of the Creative Commons Attribution Noncommercial License which permits any noncommercial use, distribution, and reproduction in any medium, provided the original author(s) and source are credited.

\section{References}

1. Anderson A, Lipscomb AB, Coulam C (1990) Antegrade curettement, bone grafting and pinning of Osteochondritis dissecans in the skeletally mature knee. Am J Sports Med 18:254261

2. Black J (1988) Orthopedic biomaterials in research and practice. Churchill Livingstone, New York, pp 292-302

3. Castillo MH, Button TM, Homs MI, Pruett CW, Doerr R (1988) Effects of radiation therapy on mandibular reconstruction plates. Am J Surg; 156:261-263

4. Cohen SB, Anderson MW, Miller MD (2003) Chondral injury after arthroscopic meniscal repair using bioabsorbable Mitek Rapidloc meniscal fixation. Arthroscopy 19:E24-E26

5. Cugat R, Garcia M, Cusco X, Monllau JC, Vilaro J, Juan X, RuizCotorro A (1993) Osteochondritis dissecans: a historical review and its treatment with cannulated screws. Arthroscopy 9:675-684

6. Dahmen G (1972) Möglichkeiten der Fixation des Knorpeltransplantats-Naht oder Kleber. Z Orthop 110:719-726

7. Dines JS, Fealy S, Potter HG, Warren RF (2008) Outcomes of osteochondral lesions of the knee repaired with a bioabsorbable device. Arthroscopy 24:62-68

8. Friederichs MG, Greis PE, Burks RT (2001) Pitfalls associated with fixation of Osteochondritis dissecans fragments using bioabsorbable screws. Arthroscopy 17:542-546

9. Gliatis J, Kouzelis A, Panagopoulos A, Lambiris E (2005) Chondral injury due to migration of a Mitek RapidLoc meniscal repair implant after successful meniscal repair: a case report. Knee Surg Sports Traumatol Arthrosc 13:280-282

10. Guhl JF (1982) Arthroscopic treatment of Osteochondritis dissecans. Clin Orthop Relat Res 167:65-74

11. Kivistö R, Pasanen L, Leppilahti J, Jalovaara P (2002) Arthroscopic repair of Osteochondritis dissecans of the femoral condyles with metal staple fixation: a report of 28 cases. Knee Surg Sports Traumatol Arthrosc 10:305-309

12. Kobayashi T, Fujikawa K, Oohashi M (2004) Surgical fixation of massive Osteochondritis dissecans lesion using cylindrical osteochondral plugs. Arthroscopy 20:981-986

13. Kumar A, Malhan K, Roberts SNJ (2001) Chondral Injury from bioabsorbable screws after meniscal repair. Arthroscopy 17:34

14. Larsen MW, Pietrzak WS, DeLee JC (2005) Fixation of Osteochondritis dissecans lesions using poly(1- Lactic acid)/poly(glycolic acid) copolymer bioabsorbable screws. Am J Sports Med 33:68-76
15. Lindèn B (1976) The incidence of Osteochondritis dissecans in the condyles of the femur. Acta orthop Scand 47:664-667

16. Mackie IG, Pemberton DJ, Maheson M (1990) Arthroscopic use of the Herbert screw in Osteochondritis dissecans. J Bone Joint Surg 72B:1076

17. Miura K, Ishibashi Y, Tsuda E, Sato H, Toh S (2007) Results of arthroscopic fixation of Osteochondritis dissecans lesion of the knee with cylindrical autogenous osteochondral plugs. Am J Sports Med 35:216-222

18. Passl R, Plenk H (1986) Ueber die Einheilung replantierter chondraler Fragmente. Unfallchirurgie 12:194-199

19. Ross G, Grabill J, Mc Devitt E (2000) Chondral injury after meniscal repair with bioabsorbable arrows. Arthroscopy 16:754756

20. Scher N, Poe D, Kuchmir F, Reft C, Weichselbaum R, Panje WR (1988) Radiotherapy of the resected Mandible following stainless steel plate fixation. Laryngoscope 98:61-563

21. Scioscia TN, Giffin JR, Allan CR, Harner CD (2001) Potential complication of bioabsorbable screw fixation for Osteochondritis dissecans of the knee. Arthroscopy 17:E7

22. Seil R, Rupp S, Dienstm MuellerB, Bonkhoff H, Kohn DM (2000) Chondral lesions after arthroscopic meniscus repair using meniscus arrows. Arthroscopy 16:E17

23. Siebold R, Dehler C, Boes L, Ellermann A (2007) Arthroscopic all-inside repair using the Meniscus Arrow: long time clinical follow-up of 113 patients. Arthroscopy 23:394-399

24. Smillie IS (1957) Treatment of Osteochondritis dissecans. J Bone Joint Surg (B) 39:248-260

25. Weckström M, Parviainen M, Kiuru MJ, Mattila VM, Pihlajamäki HK (2007) Comparison of bioabsorbable pins and nails in the fixation of adult Osteochondritis dissecans fragments of the knee: an outcome of 30 knees. Am J Sports Med 35:1467-1477

26. Widuchowski W, Widuchowski J, Trzaska T (2007) Articular cartilage defects: study of 25.124 knee arthroscopies. Knee 14:177-182

27. Wouters DB, Bos RRM, van Luyn MJA (2008) Should in the treatment of Osteochondritis dissecans biodegradable or metallic fixation devices be used? A comparative study in goat knees. J Biomed Mat Res (B) 84:154-164

28. Wouters DB, van Horn JR, Bos RRM (2003) The use of biodegradables in the treatment of Osteochondritis dissecans of the knee: fiction of future? Acta Orthop Belgica 69:175-181

29. Wouters DB, Bos RRM, Mouton LJ, van Horn JR (2004) The Meniscus Arrow ${ }^{\circledR}$ or metal screw for treatment of Osteochondritis dissecans? in Vitro comparison of their effectiveness. Knee Surg Sports Traumatol Arthrosc 12:52-57

30. Miao Y, Yu J, Zeng Z-Z, Yu C-1, Ao Y, Gong X, Wang Y, Jiang D (2009) MRI signal changes in completely healed meniscus confirmed by second-look arthroscopy after meniscal repair with bioabsorbable arrows. Knee Surg Sports Traumatol Arthrosc 17:622-631 